\title{
Can We Use E-Learning to Increase Cognitive Process on Physic Equation Understanding? A Preliminary Result
}

\author{
Sintia W. Niasari, Eddy Hartantyo \\ Physics Department \\ Faculty of Mathematics and Natural Sciences, \\ Universitas Gadjah Mada, Yogyakarta, Indonesia \\ sintia_windhi@ugm.ac.id
}

\begin{abstract}
E-learning was used widely on higher education (i.e. university). E learning also gives unlimited distance and time as long as the students have Internet connectivity. In this study, we used online learning, as one of e-learning forms, containing short video and one page PDF files. These files provide a priori knowledge for students who take Electromagnetic class on the fifth semester. Based on the theoretical framework of cognitive load theory, a priori knowledge might support the development of secondary knowledge. Thus, we want to know whether provided a priori knowledge enhances the students understanding on electromagnetic equations. One class was a control group consisted of 52 students who took electromagnetic class. Another class was an experimental group, consisted of 64 students, in the same subject who used e-learning as a combination with contemporary class. A pretest/ posttest was performed for analysis of both classes. The hypothesis that a priori knowledge increases the understanding of physics students on electromagnetic theory was confirmed. When mark of posttest of control and experimental classes were compared, it was found that correct posttest answer of the experimental group was higher than the control group. Additionally, from the experimental group, it was found that instructions about the files could increase student understanding significantly. This means that online learning should not be a repository where the lecturers can put a lot of text. Any file should be followed by instructions that help students to have better understanding.
\end{abstract}

Keywords - online learning; learning by observing; a priori knowledge

\section{INTRODUCTION}

Online learning have been suggested for educational tools [1], due to motivational aspect [2]. Online learning enables students to discover new strategies for students' own learning style [1]. Thus, online learning is more becoming part of University education particularly for international students [3]. However, there is still insufficient experimental evidence for the effectiveness of online learning for physics education in Universities.

In primary Physics education in well-developed country, online learning is often used [4]. Meta-analyses did show that in general the use of online learning in Physics education positively affects learning outcomes [5], but in these analyses were not taken for university or college students. To find evidence about the effectiveness of using online learning in
Physics education in higher degree, particularly for applied physics, we conducted an experiment.

These experiments were following new findings that more precise identification of the instructional level (i.e. the intervention group) resulted in better than the other groups on answering a question [6]. Although time duration of self-study is important [7], construct schemas helps learners to interactively automate schemas [8]. Students' behavior (time and effort) was in some cases, but not always, related to their marks [9]. Performance improved substantially by incorporating instructions and text into one session [10].

The focus was on student understanding in the middle grades of University, when students already got basic physics classes. This study examined a sample of higher education students whom took electromagnetic in the geophysics discipline (applied physics). Short video was prepared for a group experiment and one page PDF files was prepared for a group norm. The goal was to test a general hypothesis that a priori knowledge might support the development of secondary knowledge.

A. Research design

To answer our research questions, we used two experimental conditions (A and $\mathrm{B}$ ) and a control condition (C):

A: students who have a priori knowledge about Maxwell equations from a given PDF file and then watching a video about explanation of Maxwell equation.

B: students who have a priori knowledge about Maxwell equations from a given PDF file.

C: students who do not have a priori knowledge about Maxwell equations.

\section{B. Participants and in tervention program}

One class was a control group consisted of 52 students who took electromagnetic class in fifth semester of the Geophysics Study Program. These students were given a PDF file about Maxwell equation.

Another class was an experimental group, consisted of 64 students, in the same subject who used e-learning as a combination with contemporary class. This group was given a PDF file and a video about explanation of Maxwell equation. 


\section{Measurement instruments}

To measure students' ready knowledge of Maxwell equations (consisted of four equations), we gave a pretest for the students in group $\mathrm{C}$. The students were asked to write the Maxwell equation, which supposed to be given in previous year in basic physic classes.

To measure students' understanding of Maxwell equations, we gave a posttest for the students in group B. The students were asked to write the Maxwell equation, after they got a PDF file about Maxwell equation on previous week.

We also measure students' understanding of Maxwell equations group B by giving a posttest. The students were asked to write the Maxwell equation, after they got a PDF file and a short video about Maxwell equation on previous week.

\section{RESULT AND DISCUSSION}

The pairwise comparisons of the total number of students who answer correctly the posttest is given in Table 1 . We base the answers to our research questions on the results of the control condition (C). After one session for explanation of Maxwell equation, students who have no a priori knowledge (found from a pretest) were given posttest. The numbers of students who answer correctly all equations were only 3 students or $6 \%$ from its population.

TABLE I. NUMBER OF STUDENTS WHO ANSWER THE POSTTEST CORRECTLY

\begin{tabular}{|l|l|l|l|}
\hline \multirow{2}{*}{ Correct answer } & \multicolumn{3}{|c|}{ Condition } \\
\cline { 2 - 4 } & \multicolumn{1}{|c|}{$\boldsymbol{A}$} & \multicolumn{1}{c|}{$\boldsymbol{B}$} & \multicolumn{1}{c|}{$\boldsymbol{C}$} \\
\hline 4 & 52 & 6 & 3 \\
\hline 3 & 8 & 7 & 4 \\
\hline 2 & 3 & 6 & 6 \\
\hline 1 & 1 & 4 & 8 \\
\hline 0 & 0 & 29 & 31 \\
\hline
\end{tabular}

The numbers of students (in group B) who answer correctly all equations were 6 students or $12 \%$. The number of students who answer correctly all equations increased significantly for condition C, i.e. 52 students or $81 \%$.

Similarly, the numbers of students (in group B) who could not answer correctly all equations were 29 students or $66 \%$. The number of students who could not answer correctly all equations decreased significantly for condition $\mathrm{C}$, i.e. 0 students or $0 \%$.

This results; as predicted, was similar with previous study that recalls a priori knowledge improved over successive tests [11]. In this study, students' behavior was excluded in the analyses, because students' behavior demonstrated the same level of learning [12].

Further study is needed in on line learning with clear instruction, particularly to know the effect of lecturers' presence on e-learning $[13,14]$. On line course experience as opposed to outside variables such as learner and instructor characteristics also can be studied further [15].

\section{CONCLUSION}

Our findings give evidence for the possibility of increasing University students' understanding ability through an intervention in which short video and PDF files are given. When utilized in this way, a short interactive video was found to promote students' understanding in applied physics knowledge, e.g. understanding the physical meaning of Maxwell equations. Giving the PDF without explanation was not effective, indicating the importance of debriefing sessions when learning outside the contemporary class.

\section{ACKNOWLEDGMENT}

The authors would like to thank to Universitas Gadjah Mada that finances this study. Sintia W. Niasari thanks to Alexander Grayver for his suggestion about how to teach complicated physics equations in a simple way.

\section{REFERENCES}

[1] Egenfeldt-Nielsen, S. (2005). Beyond edutainment. Exploring the educational potential of computer games. Doctoral dissertation, ITUniversity of Copenhagen, Denmark.

[2] Garris, R., Ahlers, R., \& Driskell, J. E. (2002). Games, motivation, and learning: A research and practice model. Simulation \& Gaming, 33, 441-467.

[3] Williamson, B. (2009). Computer games, schools, and young people: A report for educators on using games for learning. Bristol, UK: Futurelab.

[4] Mullis, I. V. S., Martin, M. O., Foy, P., \& Arora, A. (2012). TIMSS 2011 international results in mathematics. Chestnut Hill, MA: TIMSS \& PIRLS International Study.

[5] Li, Q., \& Ma, X. (2010). A meta-analysis of the effects of computer technology on school students' mathematics learning. Educational Psychology Review, 22, 215-243.

[6] Joanna P. W., Simonne P., Abigail M. N., Anne E. S., Amaya G., Jill G. O., \& J. Grant A. (2014). An Intervention to Improve Comprehension of Cause/Effect Through Expository Text Structure Instruction. Journal of Educational Psychology, 106, 1-17.

[7] Fernández-Alonso, R., \& Suárez-Álvarez, J. (2015). Adolescents' Homework Performance in Mathematics and Science: Personal Factors and Teaching Practices. Journal of Educational Psychology, 107, 10751085 .

[8] Wouters, P., Tabbers, H. K. \& Paas, F. (2007). Interactivity in Videobased Models. Educational Psychology Review, 19, 327-342.

[9] Fukkink, R. G., Trienekens, N. \& Kramer, L. J. S. (2011). Video Feedback in Education and Training: Putting Learning in the Picture. Educational Psychology Review, 23, 45-63.

[10] Bakker, M., Heuvel-Panhuizen , M. Robitzsch, A. (2015). Effects of playing mathematics computer games on primary school students' multiplicative reasoning ability. Contemporary Educational Psychology, $40,55-71$

[11] Feeney, L. \& Meyers, S. (2016). Examining Interactive and Metacognitive Processes in Student Learning: Findings from a Hybrid Instructional Environment. Online Learning 20 (3) 110 - 125.

[12] Fritz1, C. O., Morris, P.E., Reid, B., Aghdassi, R. \& Naven, C. E. (2015). Failure of further learning: Activities, structure, and meaning. British Journal of Psychology, 106, 22-45.

[13] Dziuban, C. D., Moskal, P. D., Cassisi, J. \& Fawcett, A. (2016). Adaptive Learning in Psychology: Wayfinding in the Digital Age. Online Learning, 20, 74-96.

[14] Kozan, K. (2016). A comparative structural equation modeling investigation of the relationships among teaching, cognitive and social presence, Online Learning (20) 3210 - 227.

[15] Quiroz, R.E., Ritter, N. L., Li, Y., Newton, R. C. \& Palkar, T. (2016). Examining Interactive and Metacognitive Processes in Student Learning: Findings from a Hybrid Instructional Environment. Journal of Online Learning Research 2(2), 123-144. 